\title{
El Derecho a una Educación Inclusiva: el título como último de los obstáculos
}

\author{
Por Antonella Gonzalez y María Eugenia Fernández
}

\section{Resumen}

Este trabajo se enmarca en la Clínica Jurídica de Derechos Humanos y Discapacidad, proyecto de extensión de la Facultad de Ciencias Jurídicas y Sociales de la Universidad Nacional de La Plata.

Al hablar de educación inclusiva, es necesario aclarar algunas cuestiones acerca de los conceptos. Ante esto, nos preguntamos ¿De qué hablamos cuándo hablamos de educación inclusiva? ¿Qué es una barrera? ¿Qué es un título no homologable? Dicha toma de posición no es ingenua, sino que encierra sentidos y significados que envuelven una forma de comprender a la educación, en este caso en particular, de comprender la educación de personas con discapacidad.

Planteamos tres niveles de obstáculos: ingreso, permanencia, egreso; desde las primeras barreras que aparecen a la hora de ingresar a los establecimientos educativos, las distintas problemáticas no sólo para permanecer sino para aprender y por último, pero no menos importante, el egreso.

Nos centraremos en este último punto, enfocándonos en la titulación de las trayectorias escolares de las personas con discapacidad. Como mencionamos con anterioridad, los conceptos y prácticas invisibilizan sentidos que influyen en los derechos de las personas con discapacidad, por ello uno de nuestros objetivos es visibilizar dichas prácticas y la vulneración de derechos que generan.

\section{Educación Inclusiva}

Tal como expresa la Oficina del Alto Comisionado de las Naciones Unidas para los Derechos Humanos, el derecho a la educación es atravesado por dos principios básicos: la universalidad y la no discriminación, frente a esto puntualmente expresó que "la educación inclusiva ha sido reconocida como la modalidad más adecuada para que los Estados garanticen la universalidad y la no discriminación en el derecho a la educación. En la Convención sobre los derechos de las personas con discapacidad se señala que, para que estas personas puedan ejercer ese derecho, han de existir sistemas educativos inclusivos; en consecuencia, el derecho a la educación es un derecho a la educación inclusiva”.

La educación inclusiva, es un derecho de todas las niñas y jóvenes ${ }^{1}$ a recibir una educación de calidad que satisfaga sus necesidades básicas de aprendizaje y enriquezca sus

1 En este documento se procuró evitar el lenguaje sexista. Sin embargo, a fin de facilitar la lectura no se incluyen recursos como "@”, “x” o "-a/as". Es por ello que deseamos que se tenga en cuenta que escribiremos en genérico femenino. 
vidas, procurando desarrollar el potencial de cada persona. Se trata del proceso de identificar y responder a la diversidad de las necesidades de todas las estudiantes a través de la mayor participación en el aprendizaje, las culturas y las comunidades, y reduciendo la exclusión en la educación. Involucra cambios y modificaciones en contenidos, enfoques, estructuras y estrategias, con una visión común que incluye a todas las niñas del rango de edad apropiado y la convicción de que es la responsabilidad del sistema regular, educar a todas las niñas. (UNESCO, 2008).

La obligación de brindar educación de calidad sobre la base del principio de igualdad y no discriminación, debe interpretarse a la luz de la Convención sobre los Derechos de las Personas con Discapacidad que en su artículo 24 reconoce el derecho a la educación inclusiva, especificando que "Los Estados Partes reconocen el derecho de las personas con discapacidad a la educación. Con miras a hacer efectivo este derecho sin discriminación y sobre la base de la igualdad de oportunidades, los Estados Partes asegurarán un sistema de educación inclusivo a todos los niveles así como la enseñanza a lo largo de la vida..."

Al respecto, el Comité sobre los Derechos de las personas con Discapacidad de Naciones Unidas, órgano de interpretación y aplicación de dicho tratado internacional, siendo una guía para su implementación, en la Observación General No 4 señaló que "los Estados partes deben hacer efectivos los siguientes derechos básicos con efecto inmediato: la no discriminación en todos los aspectos de la educación y abarcar todos los motivos de discriminación prohibidos internacionalmente. El Comité entiende que la educación, conforme el marco normativo internacional, debe orientarse al pleno desarrollo del potencial humano, el sentido de la dignidad y autoestima, así como el respeto y valorización de las diferencias. Además, señala que la educación inclusiva ha de entenderse como un derecho humano fundamental, como un medio de realización de otros derechos humanos, como el derecho a la protección por igual de todas las personas ante la ley.

Además, afirmó que "Los Estados partes deben prohibir toda discriminación por motivos de discapacidad y garantizar a todas las personas con discapacidad una protección igual y efectiva contra la discriminación por cualquier motivo" y que "Entre las medidas necesarias para hacer frente a todas las formas de discriminación figuran la identificación y eliminación de las barreras jurídicas, físicas, de comunicación y lingüísticas, sociales, financieras y actitudinales en las instituciones educativas y la comunidad".

Los instrumentos normativos descriptos no son simbólicos sino que se deben aplicar y acatar para poder terminar con la desigualdad que enfrentan las personas con discapacidad que cursan los niveles de escolarización obligatorios, ya sea tanto en el ingreso, permanencia y egreso.

El derecho a una educación inclusiva se ve alterado por variadas prácticas, que provocan una situación desigual, poniéndose en jaque el derecho constitucional a la igualdad. 


\section{Conceptos que encierran sentidos}

Este trabajo se posiciona desde el modelo de derechos para comprender a la discapacidad como todas aquellas barreras que impiden la plena participación de las personas con discapacidad en la vida social en igualdad de condiciones que los demás ciudadanos. Este modelo, tiene nacimiento a través de la lucha del colectivo de personas con discapacidad que consiguen plasmar sus derechos en la Convención sobre los derechos de las personas con discapacidad (2006). Asimismo, apunta a la autonomía de la persona con discapacidad para decidir respecto de su propia vida, y para ello se centra en la eliminación de cualquier tipo de barrera, a los fines de brindar una adecuada equiparación de oportunidades (Palacios, 2008).

Según la Clasificación Internacional del Funcionamiento de la Organización Mundial de la Salud, se entiende por barreras a todos aquellos factores ambientales en el entorno de una persona que, a través de su ausencia o presencia, limitan el funcionamiento y crean discapacidad. Estos incluyen aspectos como un ambiente físico inaccesible, falta de tecnología asistencial apropiada, actitudes negativas de las personas hacia la discapacidad, así como servicios, sistemas y políticas que dificultan la participación plena en todas las áreas de la vida.

Las barreras pueden agruparse en cuatro categorías:

- Barreras físicas/ambientales: Acceso a edificaciones, escuelas, centros de salud, transporte, vías de comunicación.

- Barreras comunicacionales: informaciones en distintos formatos de lectura y escucha.

- Barreras políticas: normativas discriminatorias y ausencia de las mismas.

- Barreras actitudinales: estereotipos, estigmas y otras formas de discriminación.

El colectivo de personas con discapacidad, es uno de los grupos a los que más se les ha vulnerado sus derechos a lo largo del tiempo. La educación es uno de los derechos fundamentales de todos los seres humanos, sin distinciones ni discriminaciones, por lo que llamaremos barrera a cualquier obstáculo que no permita el ejercicio de este derecho. Para romper con estas barreras, hablamos de apoyos y adaptaciones, apoyos como todos aquellos recursos materiales y humanos que buscan romper con las barreras que obstaculizan los aprendizajes. A su vez, las adaptaciones son las modificaciones y reconfiguraciones de los contenidos curriculares para la enseñanza de los mismos, acordes con las necesidades de cada estudiante.

Las adaptaciones y apoyos para cada estudiante con discapacidad están plasmados en el Proyecto Pedagógico Individual para la Inclusión (PPI), denominado de esta manera a partir de la Resolución 311/16 del Consejo Federal de Educación. En el mismo, se presentan todas aquellas adaptaciones curriculares para que sea posible una verdadera inclusión. Se trata de modificaciones, reconfiguraciones en los contenidos prescriptos para la enseñanza 
en el Diseño Curricular y de apoyos que posibiliten el aprendizaje durante la trayectoria escolar. Todas estas acciones son las que buscan romper con las barreras que obstaculizan la permanencia de las estudiantes con discapacidad.

\section{Normativas}

- Pacto Internacional de Derechos Económicos, Sociales y Culturales del año 1976 .Reconoce el derecho de toda persona a la educación entendiendo que debe orientarse hacia el pleno desarrollo de la personalidad humana y del sentido de su dignidad. A su vez, debe capacitar a todas las personas para participar efectivamente en una sociedad libre.

- La Declaración de Salamanca del año 1994, invoca a la necesidad de actuar con miras a conseguir escuelas para todas, que celebren las diferencias, respalden el aprendizaje y respondan a las necesidades de cada una. Pone el énfasis, en que deben ser las escuelas las que respondan a las necesidades de las estudiantes, promuevan valores y posturas de no discriminación, de convivencia de la diversidad y del respeto por las diferencias.

- La Convención Interamericana para la Eliminación de todas las formas de Discriminación contra las Personas con Discapacidad del año 1999, en su Artículo 1.1 dice que "discriminación contra las personas con discapacidad significa toda distinción, exclusión o restricción basada en una discapacidad, antecedente de discapacidad, consecuencia de discapacidad anterior o percepción de una discapacidad presente o pasada, que tenga el efecto o propósito de impedir o anular el reconocimiento, goce o ejercicio por parte de las personas con discapacidad, de sus derechos humanos y libertades fundamentales".

- Desde el año 2006 se encuentra vigente la Convención por los Derechos de las Personas con Discapacidad, en donde se plasma el reconocimiento a la lucha de las personas con discapacidad en relación a sus derechos. En el Art. 24 de la misma, se reconoce el derecho a la educación inclusiva en todos los niveles del sistema educativo, sin discriminación alguna.

- Ley de Educación Nacional N²6206 del año 2006, considera a la educación y al conocimiento como bienes públicos y derechos personales y sociales que deben ser garantizados por el Estado, siendo el responsable de garantizar la enseñanza y aprendizaje de todas las sujetas de derechos. Entre los fines de la política educativa, garantizar una educación inclusiva brindando a las personas con discapacidades, permanentes o temporales, una propuesta pedagógica que permita el máximo desarrollo de sus derechos.

- Ley de Educación Provincial $N^{\circ} 13688$, del año 2007, establece en su artículo $5^{\circ}$ que la Dirección General de Cultura y Educación tiene la "responsabilidad principal e indelegable de proveer, garantizar y supervisar una educación integral, 
inclusiva, permanente y de calidad para todas sus habitantes (...)". Es por ello que la trayectoria escolar debe verse beneficiada por acciones tendientes a garantizar el ingreso, permanencia, promoción y egreso en las mejores condiciones de igualdad.

- En el Marco general de política curricular, creado en el año 2007, se expone que se debe guiar el diseño e implementación de propuestas pedagógicas específicas acordes a las estudiantes, con y sin discapacidad, reconociendo en cada una trayectorias educativas diversas.

- El Informe del Alto Comisionado del año 2013, reconoce a la educación como un derecho universal reconocido a nivel internacional, donde los estados partes asumen la responsabilidad de garantizar y facilitar dicho derecho.

- El Comité sobre los Derechos de las Personas con Discapacidad, observación general núm. 4 del año 2016, sobre el derecho a la educación inclusiva. "Las transiciones efectivas: las alumnos con discapacidad reciben apoyo para que su transición del aprendizaje escolar a la formación profesional y la enseñanza superior y, por último, el entorno laboral se realice de manera efectiva. Se desarrollan las capacidades y la confianza de las alumnas y estas reciben los ajustes razonables, son objeto de un trato igualitario en los procedimientos de evaluación y examen y se certifican sus capacidades y logros en igualdad de condiciones con los demás" (Comité sobre los Derechos de las Personas con Discapacidad. Observación general núm. 4 sobre el derecho a la educación inclusiva, 2016, p 5)

- Resolución 311/16 de promoción, acreditación, certificación y titulación de estudiantes con discapacidad del Consejo Federal de Educación viene a convalidar y hacer efectiva la normativa internacional, con jerarquía constitucional, que consagra el derecho a una educación inclusiva. En relación a su obligatoriedad la Ley de Educación Nacional 26.206 en su artículo 118 establece que "las resoluciones del Consejo Federal de Educación serán de cumplimiento obligatorio, cuando la Asamblea así lo disponga, de acuerdo con la Reglamentación que la misma establezca para estos casos". A su vez, el reglamento de Funcionamiento del Consejo Federal de Educación en su artículo 11 establece que "la Asamblea Federal se pronunciará a través de las siguientes categorías de decisiones con los alcances que en cada caso se indican: 1) Resoluciones: son de cumplimiento obligatorio para todas las jurisdicciones y se refieren a cuestiones en las que el Consejo Federal actúa como ámbito de concertación, acuerdo y coordinación de la política educativa nacional, asegurando la unidad y articulación del Sistema Educativo Nacional".

En relación al egreso de las personas con discapacidad en su anexo I Artículo $26^{\circ}$ establece que "la escuela donde desarrolla su trayectoria escolar acreditarálos saberes adquiridos". El artículo 39 expresa que "el PPI habilitará a las estudiantes con discapacidad a recibir el título y certificado analítico del Nivel o Modalidad, al igual que el resto de la población escolar, dando cuenta de su trayectoria educativa". En el Anexo IV se establece que "tal como se señala en el cuerpo del documento, las estudiantes con discapacidad que hayan contado con ajustes razonables para el acceso al currículum, contarán en su analítico 
final al igual que el resto de la población escolar la trayectoria educativa recorrida y obtendrán su título en igualdad de condiciones con las demás y sin discriminación”.

\section{El último de los obstáculos: el egreso}

El obstáculo aparece cuando el propio PPI se convierte en una barrera a la hora del egreso en igualdad de condiciones que el resto de las estudiantes sin discapacidad. Es necesario explicar que en la mayoría de los casos trabajados en la Clínica Jurídica de Derechos Humanos y Discapacidad, el PPI es confeccionado por la escuela de educación especial, quien es la encargada de realizar las orientaciones, apoyos y recursos, lo cual no es un aspecto negativo hasta el momento que esto, impide la acreditación del total de las materias por parte de la escuela común. Es decir, la escuela especial reclama la acreditación de materias troncales que convierten al título en $\mathrm{NO}$ homologable. ¿A qué nos referimos con título no homologable? Es aquel que no tiene el mismo valor al ser comparado con otro, el cual no habilita a la continuación de estudios superiores. Realizando una analogía, es similar a la situación de una persona que ha realizado sus estudios universitarios en Argentina y quiere ejercer la profesión en otro país. En ese caso, deberá demostrar que cuenta con los mismos saberes que cualquier egresado de ese país. En síntesis, al recibir un título no homologable, una joven con discapacidad encuentra truncado su derecho a la formación a lo largo de la vida y el acceso al mundo laboral. Esta situación es un claro reflejo de la discriminación que reciben las niñas y jóvenes con discapacidad por parte del sistema educativo.

En nuestro espacio de Clínica Jurídica de Derechos Humanos y Discapacidad, en el período 2016-2017 fue el tema de mayor consulta e intervención la problemática en materia de educación inclusiva, fundamentalmente en relación al egreso.

Pondremos como ejemplo los últimos dos casos recibidos.

El primero de ellos es el caso de $\mathrm{L}$, quien realizó el nivel secundario en un establecimiento de educación común de la Ciudad de La Plata, siendo una experiencia significativa y enriquecedora para su formación, lo cual se logró gracias al trabajo mancomunado entre dicha escuela, la familia, la maestra integradora, los profesionales privados y personal de la escuela especial. A la escuela concurrió de la misma forma que todas sus compañeras, con la misma carga horaria, cursando todas las materias, rindiendo exámenes finales y es por esto que nunca tuvo la necesidad de concurrir a la escuela especial. En el último año de cursada se les comunicó a él y su familia que el título de $\mathrm{L}$ al terminar el secundario no iba a ser homologable. Es decir, que no iba a ser igual al otorgado a todas sus compañeras.

El segundo caso es el de $\mathrm{F}$, que terminó el secundario en una Escuela común de la Ciudad de La Plata, Provincia de Buenos Aires. No concurría a la escuela especial y algunos años los curso sin necesidad de adaptaciones por parte de la misma. Sin embargo, al terminar el secundario le otorgan un título no homologable. Frente a ello, F y su familia

desconocían lo que implicaba un título no homologable, no sólo en el aspecto escolar, sino en su vida independiente. Luego de algunos años, F decide continuar con su formación, 
inscribiéndose en un instituto de formación docente. Dicho establecimiento le abrió las puertas pero bajo la condición de concurrir como oyente a las materias hasta regularizar su situación con el título secundario.

En estos dos casos vemos como el otorgamiento de un título no homologable afecta no solo el derecho a la educación sino también afecta a otros derechos fundamentales (a trabajar, a la vida independiente, a la igualdad de trato, entre otros).

\section{Conclusiones}

Este trabajo busca visibilizar las prácticas excluyentes y discriminatorias que se dan en el sistema educativo, especialmente en el egreso de las personas con discapacidad.

En referencia al egreso vemos un gran avance en materia normativa con la resolución 311/16 del Consejo Federal de Educación, a la cual hicimos mención anteriormente. Más allá de lo explícito de la obligatoriedad de las Resoluciones del Consejo Federal de Educación para las provincias, entendemos que el principio de no discriminación se encuentra transversalmente en ella. En relación a lo expuesto el Comité de derechos económicos, sociales y culturales en su Observación General $N^{\circ} 3$ establece que el Pacto impone varias obligaciones con efecto inmediato. Una de ellas, consiste en que los Estados se "comprometen a garantizar" que los derechos pertinentes se ejercerán "sin discriminación..." La Observación General № 9 del Comité de derechos económicos, sociales y culturales establece que "las garantías de igualdad y no discriminación deben interpretarse, en la mayor medida posible, de forma que se facilite la plena protección de los derechos económicos, sociales y culturales".

Ante esto, no solo las prácticas educativas implican un acto de discriminación y/o exclusión sino también la aplicación o no de una política pública. Dicho en otras palabras, si la Provincia de Buenos Aires no acata la resolución 311/16, es una barrera política que genera discriminación. Frente a esto es que entendemos que la Resolución 311/16 es de cumplimiento inmediato. Esto quiere decir que los títulos de L, F y todas las estudiantes con discapacidad, deben otorgarse en igualdad de condiciones que el resto de la población escolar, de lo contrario se trata de un acto claramente discriminatorio y violatorio del Derecho a la Educación.

A partir del contacto con referentes de educación en otras provincias, tenemos el conocimiento acerca de la implementación de la resolución 311/16 en ellas, siendo la provincia de Buenos Aires, la más reticente a su puesta en práctica. El sistema educativo provincial alude a que la resolución no es obligatoria y no se encuentra homologada y en el camino siguen quedando afuera personas con discapacidad con un título que no se encuentra en igualdad de condiciones que el resto de sus compañeras.

Dicho esto se entiende que se ha creado un marco que garantiza a todas las estudiantes su derecho a una educación inclusiva en igualdad de condiciones y oportunidades, el cual entiende que todas las niñas con discapacidad tienen derecho al ingreso a una escuela sin discriminación, en igualdad de condiciones; el derecho a permanecer, es decir, que se 
realicen todos los ajustes razonables y se presten los apoyos necesarios para facilitar la formación efectiva, logrando el máximo desarrollo académico y social; y la igualdad al momento del egreso. En el punto del egreso, es donde nos centramos, debido a que entendemos que es una de las problemáticas más importantes, o es allí donde, con la expedición de un título no homologable, se vuelve a estigmatizar a la persona con discapacidad. Dicho en otras palabras si se le da la posibilidad a la persona con discapacidad de ingresar a una escuela, se realizan ajustes razonables y apoyos pero su título no se otorga en igualdad de condiciones, no estaríamos frente a una verdadera educación inclusiva.

Es necesario decir que la titulación igualitaria en nuestro país es un problema sin resolver, en donde encontramos avances pero los mismos no alcanzan a las prácticas.

Comprendemos y defendemos que una educación inclusiva abarca a todos los sujetos, reconociendo a la educación como un derecho de todos los seres humanos, lo cual hace que vaya más allá de la discapacidad, en donde el papel de todos los actores educativos es primordial. Dado que estos, funcionan como una red que posibilita la comunicación, la cooperación y puesta en acción de ideas. No se trata de un logro sino de estar permanentemente en proceso de transformación, tomando una posición que posibilite la creación, mantenimiento y mejora de las condiciones necesarias para la enseñanza y el aprendizaje de todas las niñas que habitan la escuela, no solo pensando en su ingreso sino también en la permanencia y en el egreso como una abertura a nuevas posibilidades. Pensar la educación inclusiva implica posicionar a la educación como un bien supremo de todas las niñas y jóvenes, sin distinciones, al cual las políticas públicas deben responder y sobre el cual debe reconfigurarse la escuela bajo una búsqueda constante para el cumplimiento de dicho derecho. 


\section{Bibliografía}

ASOCIACIÓN CIVIL POR LA IGUALDAD Y LA JUSTICIA. (2012). Guía de análisis presupuestario con enfoque de derechos para la ciudad de Buenos Aires. Buenos Aires, Argentina : TFI

GUIDELINES FOR INCLUSION. ENSURING ACCESS TO EDUCATION FOR ALL [Orientaciones para la inclusión. Asegurar el acceso a la Educación para Todos]. (2005) Paris, UNESCO.

Chávez Penillas, F. (2014). El Derecho a la Educación de las Personas con Discapacidad. Buenos Aires, Argentina : Grupo Artículo 24.

Cobeñas, P; Fernández, C ; Galeazzi, M; Noziglia, J; Santuccione, G; Schnek, A. (2017). Educación Inclusiva y de calidad, un derecho de todos. Buenos Aires, Argentina: Grupo Artículo 24. Copidis.

Cobeñas, P. (2016). Tesis de posgrado. Jóvenes mujeres con discapacidad en escuelas públicas de la provincia de Buenos Aires: Problematizando los procesos de inclusión y exclusión educativa. La Plata, Buenos Aires: Universidad Nacional de La Plata.

CONFERENCIA MUNdial SOBRE NeCESIDAdes EdUCATIVAS EsPeCIALES: ACCESO Y CALIDAD. (1994) Declaración de Salamanca. En línea en: http://www.unesco.org/education/pdf/SALAMA_S.PDF

Congreso Nacional de la República Argentina (1995). Ley Antidiscriminación Nº 24.521. En línea en: http://servicios.infoleg.gob.ar/infolegInternet/anexos/2000024999/20465/texact.htm (2006). Ley de Educación Nacional Argentina N²6206. En línea en: http://servicios.infoleg.gob.ar/infolegInternet/anexos/2500029999/25394/texact.htm (2007). Ley de Educación Provincial Buenos Aires N¹3688. En línea en: http://www.suteba.org.ar/download/ley-de-educacin-provincial-43873.pdf

Dirección General Cultura y EduCACIÓn (2007). Marco general de política curricular. En línea en:

http://servicios.abc.gov.ar/lainstitucion/organismos/consejogeneral/disenioscurriculare s/documentosdescarga/marcogeneral.pdf

Naciones Unidas Derechos Humanos (1976). Pacto Internacional de Derechos Económicos, Sociales y Culturales. En línea en: http://www.ohchr.org/SP/ProfessionalInterest/Pages/CESCR.aspx

(2006). Convención por los Derechos de las Personas con Discapacidad. En línea en: http://www.un.org/esa/socdev/enable/documents/tccconvs.pdf 
(2013). Informe del Alto Comisionado. En línea en: http://ap.ohchr.org/documents/dpage s.aspx?s=111

(2016). Comité sobre los Derechos de las Personas con

Discapacidad. En línea en: http://www.ohchr.org/SP/HRBodies/CRPD/Pages/CRPDIndex.aspx (1999)La Convención Interamericana para la Eliminación de todas las formas de Discriminación contra las Personas con Discapacidad. En línea en: http://www.oas.org/juridico/spanish/tratados/a-65.html

PAlacios, A. (2008). El modelo social de discapacidad: orígenes, caracterización y plasmación en la Convención Internacional sobre los Derechos de las Personas con Discapacidad. Argentina: Grupo editorial CINCA. 